\title{
Dilemma of Approaches to Thoracic and Lumbar Spine: Our 10 Years' Review
}

\author{
Parthasarathi Datta ${ }^{1}$ Debajit Roy Barman ${ }^{2}$ Rahul Varshney ${ }^{1}$ Shuvankar Mukherjee ${ }^{3}$ Sarmila Sen ${ }^{4}$ \\ Nani Sen ${ }^{1}$ Santanu Ghosh ${ }^{1} \quad$ B. C. Mohanty ${ }^{1}$ Pulak Deb $^{1}$
}

\footnotetext{
${ }^{1}$ Department of Neurosurgery, Calcutta National Medical College and Hospital, Kolkata, West Bengal, India

2 Department of Neurosurgery, NRS Medical College and Hospital, Kolkata, West Bengal, India

${ }^{3}$ Department of Community Medicine, Calcutta National Medical College, Kolkata, West Bengal, India

${ }^{4}$ Department of Pathology, Calcutta National Medical College,

Kolkata, West Bengal, India
}

Indian J Neurosurg 2015;4:157-163.

\author{
Address for correspondence Parthasarathi Datta, MCh, Department \\ of Neurosurgery, Calcutta National Medical College and Hospital, \\ Kolkata, West Bengal 700014, India \\ (e-mail: psdatta2010@gmail.com).
}

\author{
Abstract \\ Keywords \\ - columns \\ - radiculomyelopathy \\ - thoracic \\ - lumbar
}

Background Lesions of the thoracic and lumbar spine are numerous. These lesions affect one or more columns (anterior, middle, and posterior) of the spine and compress the spinal cord either from anterior or posterior, giving rise to the features of radiculomyelopathy. These lesions can be approached either from the anterior or posterior aspect of the spine. We present our past 10 years' experience regarding the comparison between the two approaches.

Methods Retrospective analysis of records of all patients with thoracic and lumbar lesion treated in our hospital between January 2005 and June 2014 was performed. Over the past 10 years, we came across 186 patients of thoracic and lumbar lesion who were operated either by anterior or posterior approach and were the focus of this study. Follow-up ranged from 6 months to 7 years.

Results All the patients presented with neurological deficits. They were evaluated with investigation protocol of our hospital. Anterior approach was done in 38 cases $(n=38)$, and posterior approach was done in 148 cases $(n=148)$. We compared between the two groups in terms of perioperative complications, recovery, persisting symptoms, and mortality.

Conclusion Complete recovery is better in the posterior approach (74.3 vs. 52.6\%) and morality is more in the anterior approach (7.9 vs. $1.3 \%)$.

\section{Introduction}

Royle $^{1}$ in 1928 described anterior decompression of thoracic spine for scoliotic deformity. Hodgson and Stock $^{2}$ later described that anterior decompressions were not associated with spinal stabilization and the patients suffered postoperative instability and deformity. Ventral instrumentation was done by Humphries and $\mathrm{Hawk}^{3}$ in 1958 , by Dwyer et $a l^{4,5}$ and by Zielke et $\mathrm{al}^{6}$ in 1970 . But

received

April 7, 2015

accepted after revision

June 26, 2015

published online

December 16, 2015
DOI http://dx.doi.org/

$10.1055 / \mathrm{s}-0035-1568993$. ISSN 2277-954X. these constructs were not rigid. In the late 1970s, Dunn ${ }^{7,8}$ developed double-rod, double-screw construct. Since then, development has occurred in anterior construct design. The newer generation titanium constructs are magnetic resonance imaging (MRI) compatible and technically simple.

The lesions / pathologies which were treated in our series include trauma, infection (tuberculosis [TB]), deformity (kyphosis, scoliosis, etc.), metastasis, and osteoporosis.

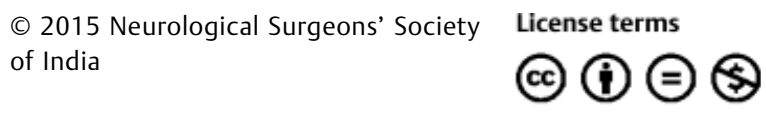


Our study was performed (1) to compare the outcome of patients undergoing surgery by anterior and posterior approaches and (2) to compare the technical aspects of anterior and posterior operation. Our literature search did not reveal any study comparing anterior and posterior approach in such multiple disease pathologies.

\section{Materials and Methods}

This is a retrospective study conducted at a tertiary care neurosurgical center. Patient records, operation notes, radiology, and outpatient files were scrutinized to collect data. Between January 2005 and June 2014, we have managed 186 patients (age range: 3-65 years; male: female $=2: 1$ ) with thoracic and lumbar pathologies via anterior or posterior approaches.

Inclusion criteria for anterior approaches are:

- Significant anterior compression of the spinal cord \pm kyphotic deformity

- Absence of thoracic or abdominal pathologies which hinder the transthoracic or retroperitoneal approaches

- Anterior and middle column disruption

Inclusion criteria for posterior approaches are:

- Significant posterior compression of the spinal cord \pm kyphotic deformity

- Patient condition not permitting lengthy anterior procedure

- Posterior column disruption

It is recommended that, if the posterior elements of spine are injured significantly, an anterior construct may be insufficient to resist flexion forces. Loss of posterior tension band may require supplementation with posterior stabilization. In our series, we have not done both anterior and posterior stabilization in the same patient due to financial constraints.

\section{Pathology}

The most common pathology/lesion in our series was trauma (110), followed by TB (42) (-Table 1).

\section{Clinical Feature}

The most common presenting complaint was pain and tenderness in 158 (85\%) patients. The pain was localized, dull, aching, or lancinating with radiation. Motor symptom was present in 110 (59\%) patients in the form of paraplegia,

Table 1 Pathology of thoracic and lumbar lesions $(n=186)$

\begin{tabular}{|l|l|}
\hline Disease (pathology) & Number \\
\hline Trauma & 110 \\
\hline Tuberculosis & 42 \\
\hline Deformity (kyphosis/scoliosis) & 24 \\
\hline Metastasis/osteoporosis & 10 \\
\hline
\end{tabular}

paraparesis, or truncal weakness. Bladder/bowel involvement was present in $83(45 \%)$ patients in the form of hesitancy, urinary retention, overflow incontinence, urge incontinence, and constipation. Spinal deformity was present in 92 (49\%) patients in the form of kyphosis, gibbus, and kyphoscoliosis (-Fig. 1).

Sensory symptom was present in $41(22 \%)$ patients in the form of complete or partial sensory loss, tingling, band-like sensation, and abnormal sensations like burning and walking on cotton, wool, etc. (-Fig. 1).

One or more clinical features were present in the same patient (-Fig. 2).

\section{Radiological Features}

All the patients had radiological investigation in the form of X-ray thoraco-lumbar (T-L) spine (anteroposterior and lateral) and MRI T-L spine \pm contrast. Cord compression was the most common radiological finding in 95 (51.05\%) patients. More than one radiological feature was present in many patients. The radiological features are depicted in - Fig. 3 (see also - Fig. 4).

\section{Operative Approaches}

The approaches to thoracic and lumbar spine were from either anterior or posterior (-Table 2 ).

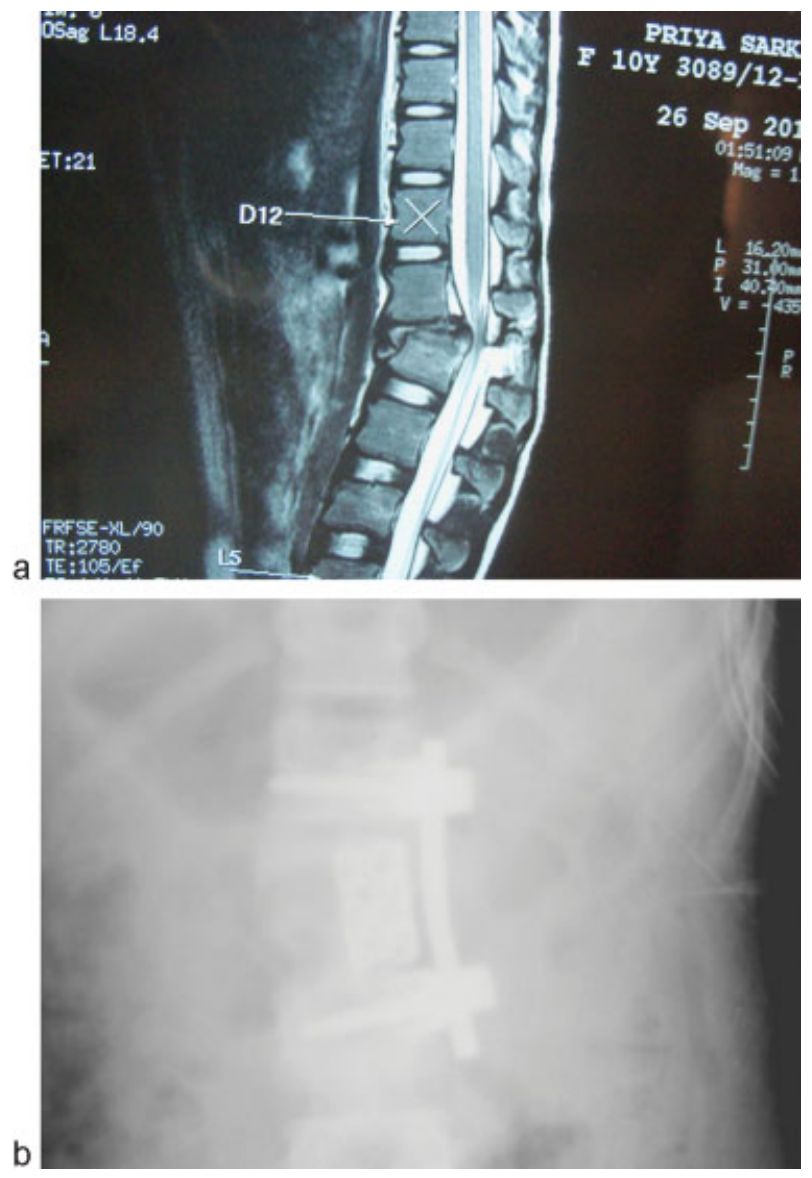

Fig. 1 (a) Traumatic fracture-dislocation of L2 vertebrae without compression of neural elements. (b) Transthoracic anterior decompression with caging and fixation. 


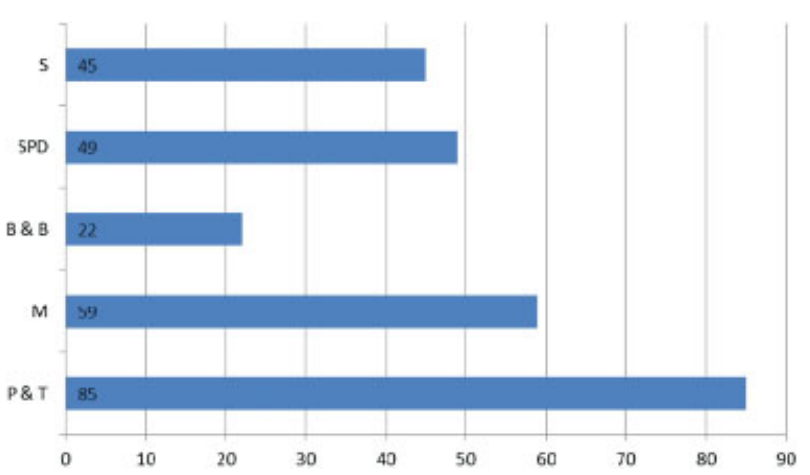

Fig. 2 Clinical features. S, sensory symptoms; SPD, spinal deformity; $\mathrm{B} \& \mathrm{~B}$, bladder and bowel symptoms; $\mathrm{M}$, motor symptoms; P\&T, pain and temperature.
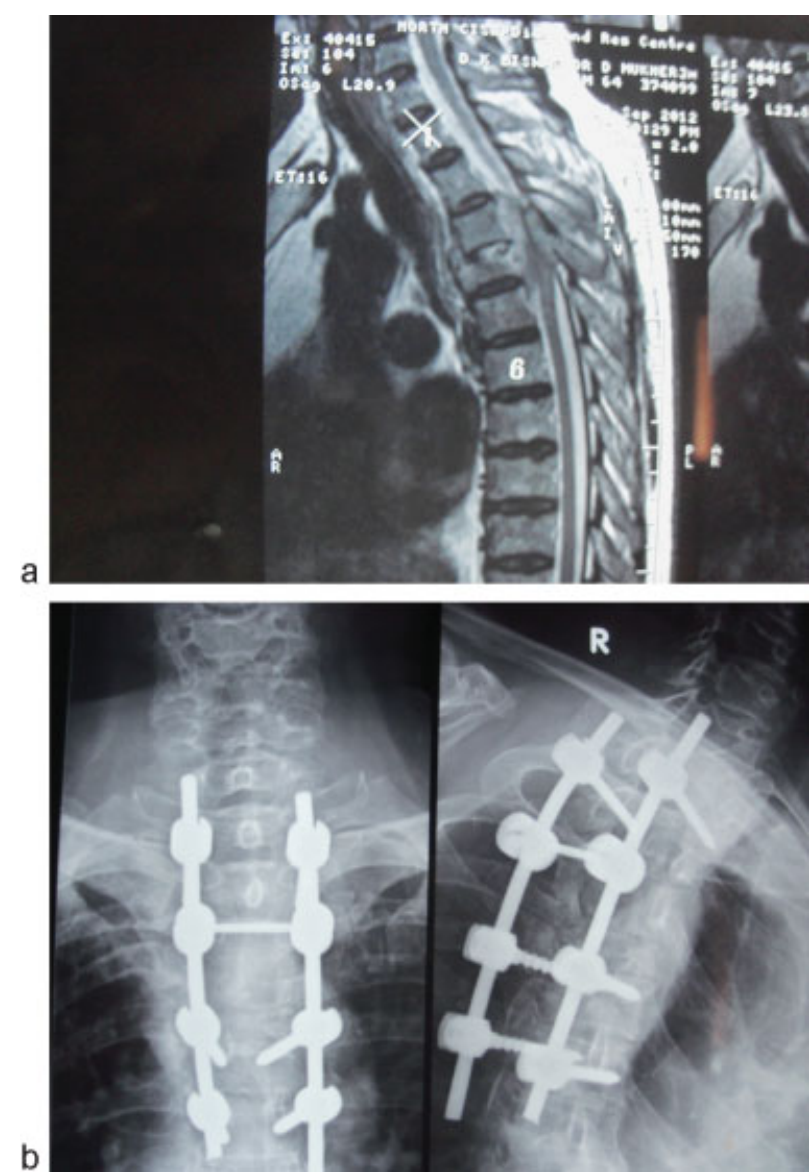

Fig. 3 (a) Tubercular involvement of D3-D4 vertebrae with cord compression.(b) Transpedicular decompression and fixation.

\section{Operative Technique}

Transpleural thoracotomy: Left-sided approach is done for lesions below T4 vertebra and right-sided approach is done for lesions above T4 vertebra. Double-lumen tube intubation is done for upper thoracic interventions.

The following are the steps of transpleural thoracotomy:

- Lateral position with sand bag below the flanks

- Incision starts $4 \mathrm{~cm}$ from spinous process and extends to

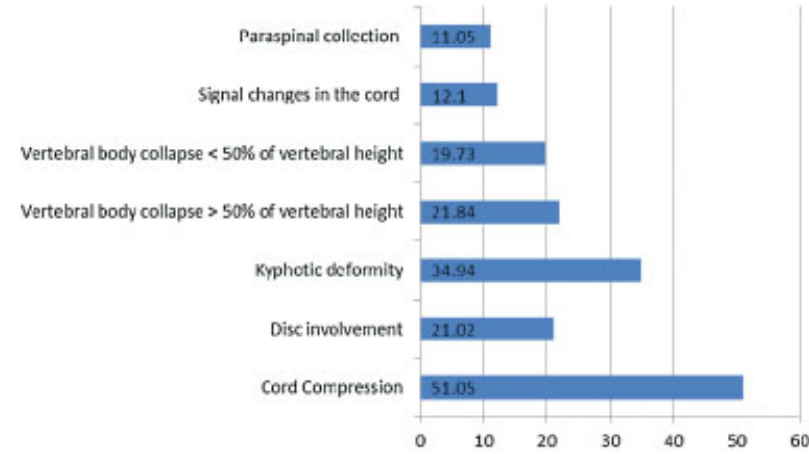

Fig. 4 Radiological features

the midaxillary line over the rib which is two level above the area of pathology

- Rib is transected starting from 1 to $2 \mathrm{~cm}$ lateral to the costotransverse joint up to the anterior part

- Endothoracic fascia and parietal pleura incised

- Chest retractor

- Lung deflated

- Prevertebral fascia

- C-arm guidance for localization

- For exposure of T-L junction, the lateral attachments of the diaphragm are incised

- Adjacent discectomy and corpectomy of involved vertebra

- Upper and lower healthy vertebra are distracted

- Titanium cage

- Fixation

- Chest drain

- Wound closure

\section{Results}

The results of anterior and posterior approaches were analyzed in terms of outcome, complications, and improvement of signs and symptoms.

\section{Statistical Analysis}

Data collected were analyzed by software SPSS version 19 (Statistical Package for Social Scientists; IBM, Chicago, United

Table 2 Approaches to different disease pathology $(n=186)$

\begin{tabular}{|l|l|}
\hline Type of operation & No. (\%) \\
\hline Anterior approach & 32 \\
\hline Transthoracic transpleural & 5 \\
\hline Retroperitoneal & 1 \\
\hline Median sternotomy & 140 \\
\hline Posterior approach & 4 \\
\hline Transpedicular decompression + fixation & 3 \\
\hline Costotransversectomy & 1 \\
\hline Vertebroplasty & \\
\hline Harrington rod &
\end{tabular}


Table 3 Complications

\begin{tabular}{|l|l|l|}
\hline & Anterior approach $(\boldsymbol{n}=\mathbf{3 8})$ & Posterior approach $(\boldsymbol{n}=\mathbf{1 4 8})$ \\
\hline Wound infection & 4 & 25 \\
\hline Persistent neurological deficit & 8 & 10 \\
\hline Worsened neurological deficit & 1 & 2 \\
\hline Persistent deformity (kyphosis)/symptoms & 10 & 20 \\
\hline Chest complications & 2 & 5 \\
\hline Postoperative hydrocephalus and tubercular meningitis & 2 & 1 \\
\hline Injury to internal organs like lungs, aorta, dura & 7 & 20 \\
\hline Lost to follow-up & 5 & 30 \\
\hline Mortality & 3 & 2 \\
\hline
\end{tabular}

States). Z-test and chi-square tests were applied to find out the associations between different variables. A $p$-value of less than 0.05 was considered to be significant.

\section{Complications}

The complications of anterior and posterior approaches are depicted in - Table 3.

Persistent deformity/symptoms signify that the patients in this group did not have complete recovery. The preoperative status (pain, bladder/bowel, motor and sensory symptoms, and deformity) was either partially or incompletely relived.
The neurological function at presentation and at follow-up was graded using the Frankel classification. The spinal deformity (kyphosis, scoliosis) was graded by measuring Cobb angle in short term (immediately after operation) and long term (after 5 years). Pain and bladder/ bowel were graded by subjective experience of the patients.

Mortality was due to pulmonary complications (pneumonia, atelectasis, pulmonary edema, respiratory tract infection, prolonged ventilator support and its consequences), prolonged recumbency (bed sores, deep vein thrombosis), sepsis, and urinary tract infection.

Table 4 Outcome

\begin{tabular}{|l|l|l|l|}
\hline & Anterior approach $(\boldsymbol{n}=\mathbf{3 8})$ & Posterior approach $(\boldsymbol{n}=148)$ & $Z$ - and $p$-values \\
\hline 1. Complete recovery & $20(52.6)$ & $110(74.3)$ & $Z=2.40 ; p=0.016^{\mathrm{a}}$ \\
\hline 2. Persisting deformity/symptoms & $10(26.3)$ & $20(13.5)$ & $Z=1.67 ; p=0.096$ \\
\hline 3. Complications & $16(42.1)$ & $53(37.8)$ & $Z=0.30 ; p=0.765$ \\
\hline 4. Mortality & $3(7.9)$ & $2(1.3)$ & $Z=2.60 ; p=0.009^{\mathrm{a}}$ \\
\hline 5. Lost to follow-up & $2(5.3)$ & $30(20.3)$ & $Z=1.94 ; p=0.052$ \\
\hline
\end{tabular}

Note: Multiple outcomes are presented in some cases.

asignificant difference between the two approaches.

Table 5 Improvement of signs and symptoms according to different approaches

\begin{tabular}{|l|l|l|l|l|l|l|l|l|}
\hline & \multicolumn{3}{|l|}{ Anterior approach } & \multicolumn{3}{l|}{ Posterior approach } \\
\hline & Improved & $\%$ & Not improved & $\%$ & Improved & $\%$ & Not improved & $\%$ \\
\hline Pain and tenderness $(n=158)$ & $30 / 38$ & 78.9 & $8 / 38$ & 21.9 & $90 / 120$ & 75 & $30 / 120$ \\
\hline Motor symptoms $(n=110)$ & $22 / 30$ & 73.3 & $8 / 30$ & 26.7 & $60 / 80$ & 75 & $20 / 80$ \\
\hline Sensory symptoms $(n=92)$ & $18 / 23$ & 78.26 & $5 / 23$ & 21.7 & $50 / 60$ & 83.3 & $10 / 60$ & 25 \\
\hline Spinal deformity $(n=41)$ & $26 / 32$ & 81.2 & $6 / 32$ & 18.8 & $40 / 60$ & 66.7 & $20 / 60$ & 16.7 \\
\hline Bladder/bowel involvement $(n=83)$ & $6 / 11$ & 54.5 & $5 / 11$ & 45.5 & $20 / 30$ & 66.7 & $10 / 30$ & 23.3 \\
\hline
\end{tabular}

Note: Pain and tenderness: $X^{2}(1)=0.25, p=0.61$.

Motor symptoms: $X^{2}(1)=0.03, p=0.85$.

Sensory symptoms: $\chi^{2}(1)=0.29, p=0.59$.

Spinal deformity: $\chi^{2}(1)=2.19, p=0.138$.

Bladder/bowel involvement: $\chi^{2}(1)=0.51, p=0.475$. 
Table 6 Short- and long-term correction of spinal deformity by the two approaches

\begin{tabular}{|l|l|l|l|l|}
\hline \multirow{2}{*}{ Approach } & \multicolumn{3}{|l|}{ Short-term correction } & \multicolumn{2}{l|}{ Long-term correction } \\
\cline { 2 - 5 } & Corrected & Not-corrected & Corrected & Not corrected \\
\hline Anterior $(n=32)$ & $28(87.5 \%)$ & $4(12.5 \%)$ & $26(81.2 \%)$ & $6(18.8 \%)$ \\
\hline Posterior $(n=60)$ & $50(83.3 \%)$ & $10(16.7 \%)$ & $40(66.7 \%)$ & $20(33.3 \%)$ \\
\hline
\end{tabular}

\section{Outcome}

The outcomes of anterior and posterior approach are depicted in - Table 4.

Complete recovery was significantly higher in the posterior approach than in the anterior approach (74.3 vs. 52.6\%; $p=0.016$ ). Mortality was significantly higher in anterior approach than in the posterior approach (7.9 vs. $1.3 \% ; p=0.009)$.

Improvement of signs and symptoms: Improvement of signs and symptoms in anterior and posterior approaches is depicted in - Tables 5 and $\mathbf{6}$.

Thus, improvement of signs and symptoms does not have a significant difference in anterior and posterior approaches.

Short-term correction (immediately after operation) was not significantly different between the two approaches $\left(\chi^{2}(1)=0.28 ; p=0.59\right)$. Also long-term correction (after 5 years) was not significantly different between the two approaches $\left(\chi^{2}(1)=0.22 ; p=0.14\right)$.

\section{Discussion}

Lesions of the T-L spine are multiple and these lesions can be approached surgically from either anterior or posterior. The anterior and posterior approaches are of various types. In the present series, we have analyzed the different lesions/ pathologies of thoracic and lumbar spine, the surgical approaches, and complications and outcomes of different approaches. We have operated 186 patients (anterior approach in 38 and posterior approach in 148) over a period of 10 years.

After analyzing statistically, we have found that (1) complete recovery is better in the posterior approach,

(2) mortality is higher in the anterior approach, and

(3) improvement of signs and symptoms including correction of spinal deformity in the short and long term does not have any statistical difference in the two approaches.

We searched the literature to see the results of different series when comparing anterior and posterior approaches.

Garg et $\mathrm{al}^{9}$ analyzed 70 patients of T-L TB via anterior and/ or posterior approaches and came to the conclusion that (1) kyphosis correction is better in posterior instrumentation (72.8 vs. $52.27 \%$ ) and (2) posterior approach has less mortality and complications.

Lin et $\mathrm{al}^{10}$ analyzed 64 patients of T-L burst fractures by anterior and posterior approaches and came to the conclusion that less intraoperative blood loss, complications, and shorter operative time are the significant advantages of posterior surgery.
Chen et $\mathrm{al}^{11}{ }^{11}$ in their review of 36 patients of chronic T-L fractures, opined that hemothorax, abdominal distension, and constipation were fewer in posterior approach; postoperative pulmonary function and correction of kyphosis were better in posterior approach $(p<0.05)$.

Arts et al ${ }^{12}$ operated 56 patients by minithoracotomy and 44 patients by transpedicular approach in thoracic disc herniations and came to the conclusion that complication rate (pulmonary morbidity) was higher in transthoracic approach, neurological complications were same, and large paramedian calcified herniated disc can be treated from posterior as well.

Aly et $\mathrm{al}^{13}$ reviewed unstable T-L burst fractures by anterior and posterior approaches and concluded that operative time was shorter in posterior approach than in anterior approach (median 171 vs. 242 minutes), blood loss was smaller in posterior approach (median 550 vs. 1,120 $\mathrm{mL}$ ), the average correction of kyphotic angle was larger in posterior group than anterior but not at final follow-up $(p>0.05)$, and the average loss of correction was also higher in the posterior group than in the anterior group $(p>0.05)$. There was no significant difference in neurological outcome.

Franic et $\mathrm{al}^{14}$ analyzed anterior versus posterior approaches in 3D correction of adolescent idiopathic thoracic scoliosis in 10 patients and concluded that both instrumentations provide similar reduction of frontal Cobb angle, long-term effects of correction of sagittal Cobb angle is better by posterior approach, and anterior approach was more effective in reduction of apical vertebral rotation.

Tuma et $\mathrm{al}^{15}$ operated 20 patients by posterior and 10 patients by anterior instrumentation in unstable $\mathrm{T}-\mathrm{L}$ fractures and did not find any statistical difference in outcome.

Philippe et al $^{16}$ treated 22 patients by posterior and 15 patients by anterior approach in T-L fracture and concluded that the two procedures gave similar final results, but an early surgery was necessary in the case of a posterior approach, whereas correction remained possible after a greater delay with the anterior procedure.

Stancić et $\mathrm{al}^{17}$ operated 13 patients by anterior and 12 patients by posterior approach in unstable T-L burst fractures and did not find any significant difference in terms of neurological improvement or economic or functional outcome. The operation time and blood loss were less in posterior approach.

$\mathrm{Xu}$ et $\mathrm{al}^{18}$ operated 179 patients by anterior and 152 patients by posterior approach in T-L burst fracture and found no difference in terms of neurological recovery, return 
Table 7 Comparison between anterior and posterior approaches to thoracolumbar spine

\begin{tabular}{|l|l|l|}
\hline Approach & Merits & Demerits \\
\hline \multirow{5}{*}{ Anterior } & Better resection of vertebra & More visceral and vascular injury \\
\cline { 2 - 3 } & Better decompression of anterior compression & $\begin{array}{l}\text { Longer hospital stay } \\
\text { More complicated than posterior }\end{array}$ \\
\cline { 2 - 3 } & Better anterior support & Prolonged operation time \\
\cline { 2 - 3 } & Better correction of short segment deformity & $\begin{array}{l}\text { More blood loss } \\
\text { Longer length of incision } \\
\text { Postoperative chest and abdominal complaints } \\
\text { More higher cost }\end{array}$ \\
\hline & Short operation time & Difficult to resect vertebra \\
\cline { 2 - 4 } & Short hospital stay & Difficult to give multilevel anterior support \\
\cline { 2 - 3 } & Less blood loss & \\
\cline { 2 - 3 } & Less postoperative chest and abdominal complaints & \\
\cline { 2 - 3 } & Less cost & \\
\cline { 2 - 3 } & Suitable in cases of other pathologies in chest/abdomen & \\
\cline { 2 - 3 } & Suitable for decompressing posterior compression & \\
\hline & Suitable for long segment deformity correction & \\
\hline
\end{tabular}

to work, complications, and Cobb angle correction. The anterior approach has longer operative time, greater blood loss, and higher cost.

Wu et $\mathrm{al}^{19}$ operated 24 patients by anterior, 38 patients by posterior, and 32 patients by paraspinal approach in T-L burst fracture and concluded that the anterior approach is convenient for resection of the vertebra and reconstruction of vertebral height but is more complicated and traumatic. The average operation time, blood loss, length of incision, and postoperative disability were lower in paraspinal/ posterior approach.

Freudenberger et $\mathrm{al}^{20}$ operated 29 patients by anterior and 30 patients by posterior approach and opined that anterior lumbar interbody fusion (ALIF) with anterior plating and posterior lumbar interbody fusion with pedicle screw fixation had similar fusion and functional outcome, but ALIF group has significantly shorter surgical time and decreased blood loss.

Erickson et $\mathrm{al}^{21}$ treated 85 patients by anterior and 39 patients by posterior approach in T-L idiopathic scoliosis and concluded that posterior procedure allows greater curve correction at the expense of more fused levels. Anterior procedure requires significantly more operative time and has longer hospitalization.

Elasawaf et $\mathrm{al}^{22}$ analyzed late outcomes in T-L fractures by anterior (30 patients) and posterior (30 patients) approaches and concluded that (1) both groups have satisfactory outcome regarding pain relief and return to work and (2) there is an increase in postoperative kyphosis in the posterior group, which is secondarily due to inability of the posterior group to provide significant anterior column support.

Muschik et al $^{23}$ operated 37 patients by anterior and 104 patients by posterior approach in idiopathic T-L scoliosis and concluded that balance of the spine is improved by the anterior technique, but is declined by the posterior technique.

After analyzing our series and different other series, we came to the conclusion that there are different merits and demerits of the anterior and posterior approach. These have been summarized in -Table 7.

\section{Conclusion}

In our series, posterior approach gives better complete recovery than anterior approach and anterior approach has greater mortality than posterior approach, whereas improvement of signs and symptoms is comparable in the two approaches.

However, in deciding which approach to adopt, the surgeon's familiarity with one approach, availability of thoracic or abdominal surgeons, and comorbidities on the part of the patient are major determining factors.

\section{References}

1 Royle ND. The operative removal of an accessory vertebra. Med J Aust 1928;1:467-468

2 Hodgson AR, Stock FE. Anterior spinal fusion a preliminary communication on the radical treatment of Pott's disease and Pott's paraplegia. Br J Surg 1956;44(185):266-275

3 Humphries AW, Hawk WA. Anterior fusion of the lumbar spine using an internal fixative device. Surg Forum 1958;9:770-773

4 Dwyer AF, Newton NC, Sherwood AA. An anterior approach to scoliosis. A preliminary report. Clin Orthop Relat Res 1969; 62(62):192-202

5 Dwyer AF, Schafer MF. Anterior approach to scoliosis. Results of treatment in fifty-one cases. J Bone Joint Surg Br 1974;56(2): 218-224

6 Zielke K, Stunkat R, Beaujean F. Ventrale derotationsspondylodesis (author's transl) [in German]. Arch Orthop Unfallchir 1976;85(3):257-277 
7 Dunn HK. Anterior stabilization of thoracolumbar injuries. Clin Orthop Relat Res 1984;(189):116-124

8 Dunn HK. Anterior spine stabilization and decompression for thoracolumbar injuries. Orthop Clin North Am 1986;17(1):113-119

9 Garg B, Kandwal P, Nagaraja UB, Goswami A, Jayaswal A. Anterior versus posterior procedure for surgical treatment of thoracolumbar tuberculosis: a retrospective analysis. Indian J Orthop 2012;46(2):165-170

10 Lin B, Chen ZW, Guo ZM, Liu H, Yi ZK. Anterior approach versus posterior approach with subtotal corpectomy, decompression, and reconstruction of spine in the treatment of thoracolumbar burst fractures: a prospective randomized controlled study. J Spinal Disord Tech 2011 (e-pub ahead of print)

11 Chen ZW, Ding ZQ Zhai WL, et al. Anterior vs. posterior approach in the treatment of chronic thoracolumbar fractures. Orthopedics 2012;35:219-224

12 Arts MP, Bartells RHMA. Anterior and posterior approach of thoracic disc herniation? A comparative cohort of mini-thoracotomy versus transpedicular discectomies. Spine J 2013;14:1654-1662

13 Aly T, Sayed ME, Ewais W. Surgical management of unstable thoracolumbar burst fractures: anterior versus posterior surgery. J Spine Neurosurg 2013; doi: 10.4172/2325-9701.1000124

14 Franic M, Tilzac MK, Pozar M, et al. Anterior vs. posterior approach in 3D correction of idiopathic thoracic scoliosis: a meta-analysis. J Pain 2012;98:795-802

15 Tuma M, Bagadatoglu H, Boyar B, et al. Anterior vs posterior instrumentation in the treatment of unstable thoracolumbar fractures: A retrospective analysis of 30 cases. Turk Neurosurg 1999;9:8-15
16 Philippe G, Marjorie S, Marc P. Isolated anterior approach or isolated post approach in the management of thoracolumbar spine fractures? J Bone Joint Surg Br 2004;86-B(Supp III):296

17 Stancić MF, Gregorović E, Nozica E, Penezić L. Anterior decompression and fixation versus posterior reposition and semirigid fixation in the treatment of unstable burst thoracolumbar fracture: prospective clinical trial. Croat Med J 2001;42(1):49-53

18 Xu GJ, Li ZJ, Ma JX, Zhang T, Fu X, Ma XL. Anterior versus posterior approach for treatment of thoracolumbar burst fractures: a meta-analysis. Eur Spine J 2013;22(10):2176-2183

$19 \mathrm{Wu} \mathrm{H}$, Wang CX, Gu CY, et al. Comparison of three different surgical approaches for treatment of thoracolumbar burst fracture. Chin J Traumatol 2013;16(1):31-35

20 Freudenberger C, Lindley EM, Beard DW, Reckling WC, Williams A, Burger EL, Patel VV. Posterior versus anterior lumbar interbody fusion with anterior tension band plating: retrospective analysis. Orthopedics 2009;32(7):492

21 Erickson MA, Kuklo TR, Emans JB, Puno RM, Mc Carthy RE. Prospective analysis comparing anterior vs. posterior approach for treatment of thoracolumbar idiopathic scoliosis. Spine 2009; $10: 53$

22 Elasawaf A. Late outcome of anterior vs. posterior fixation for thoracolumbar fractures. Int Res J Basic Clin Stud 2013;1(2): 22-31

23 Muschik MT, Kimmich H, Demmel T. Comparison of anterior and posterior double-rod instrumentation for thoracic idiopathic scoliosis: results of 141 patients. Eur Spine J. 2006 Jul;15(7): $1128-1138$ 